\title{
Characteristics of low latitude ionospheric E-region irregularities linked with daytime VHF scintillations measured from Varanasi
}

\author{
K PAtel ${ }^{1}$, A K Singh ${ }^{1, *}$, R P PATEL ${ }^{2}$ and R P Singh ${ }^{1,3}$ \\ ${ }^{1}$ Atmospheric Research Laboratory, Department of Physics, Banaras Hindu University, \\ Varanasi 221 005, India. \\ ${ }^{2}$ Department of Physics, M.M.H. P.G. College, Ghaziabad, India. \\ ${ }^{3}$ Veer Kunwar Singh University, Ara, Bihar, India. \\ *e-mail: abhay_s@rediffmail.com
}

\begin{abstract}
VHF amplitude scintillations recorded during the daytime period from January 1991 to December 1993, April 1998 to December 1999 and January 2008 to December 2008 at low latitude station Varanasi (geographic lat. $=25^{\circ} 15^{\prime} \mathrm{N}$; long. $=82^{\circ} 59^{\prime} \mathrm{E}$; geomagnetic lat. $=14^{\circ} 55^{\prime} \mathrm{N}$, long. $=154^{\circ} \mathrm{E}$, dip angle $=37.3^{\circ}$, sub-ionospheric dip $=34^{\circ}$ ) have been analyzed to study the behaviour of ionospheric E-region irregularities during the active solar and magnetic periods. The autocorrelation functions, power spectral densities, signal de-correlation times are computed to study the temporal features of ionospheric E-region irregularities linked with daytime scintillations. Derived spectral index ranges between -2 and -9 . Assuming velocity of irregularities, the characteristic lengths of the E-region irregularities are estimated. We have estimated the minimum and maximum range of scale length of sporadic-E $\left(E_{s}\right)$ irregularities to be observed over Varanasi. These results are in close agreement with those reported from this latitude region.
\end{abstract}

\section{Introduction}

The daytime scintillations studies have not received as much attention as night-time scintillations because of their relatively lower occurrence rate. The night-time scintillations are mainly attributed to spread-F, whereas daytime scintillations are linked to E-region irregularities (Anastassiadis et al 1970; DasGupta and Kersley 1976; Rastogi and Iyer 1976; Basu et al 1977; Ogawa et al 1989; Hajkowicz and Minakoshi 2003). Aarons and Whitney (1968) considered the daytime scintillations observed at Sangamore hill (dip $\left.73^{\circ} \mathrm{N}\right)$ to be due to sporadic-E $\left(E_{s}\right)$ cloud and estimated the horizontal dimension to be $300-600 \mathrm{~km}$. After simultaneous observations of vertical soundings and the Faraday fadings of the beacons from a low orbiting satellite, Rastogi and Iyer (1976) showed the existence of cloud of intense $E_{s}$ in the path of radio waves, which produced scintillation even during the daytime at low latitudes. Ogawa et al (1989) using orbiting 'Transit' satellites in the summer of 1986 showed daytime maximum scintillation occurrence coinciding with a wellknown anomalous peak in the occurrence of $E_{s}$ over Japan. Daytime scintillations are seen to be a regular phenomenon in ATS 6 beacons $(41 \mathrm{MHz}$ and $140 \mathrm{MHz}$ ) recorded at Huancayo, Peru, near magnetic equator (Basu et al 1977). Recently, Hajkowicz and Minakoshi (2003) have made a comprehensive evaluation of VHF ionospheric scintillation morphology in East Asia (Kokobunji, Japan) and concluded that daytime scintillations are due to the occurrence of $E_{s}$.

During daytime the electrojet region generates plasma density irregularities, which may be

Keywords. Daytime scintillations; ionospheric E-region irregularities; ionospheric propagation; wave propagation. 

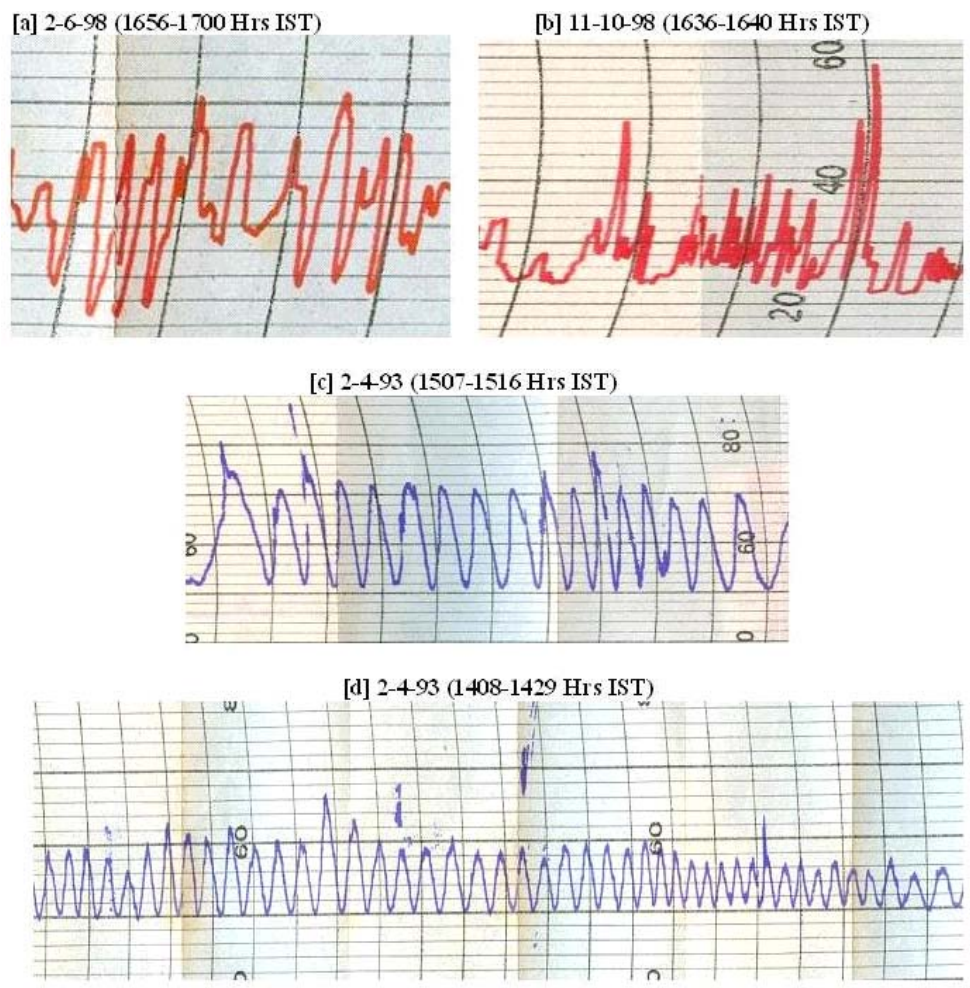

Figure 1. Typical examples of different types of daytime scintillations observed at Varanasi: (a) type A, weak scintillation with slow fading rate on 2-6-98 (16:56-17:00 h IST), (b) type B, weak scintillation with fast fading rate on 11-10-98 (16:36-16:40 h IST), (c) type C, quasi-periodic scintillations with ringing pattern on 2-4-93 (15:07-15:16 h IST) and (d) type D, long duration periodic scintillation with ringing pattern on 2-4-93 (14:08-14:29 h IST).

associated with the observed daytime scintillations. Goodman (1967) reported that the occurrence of pronounced scintillation of radio waves transmitted from the synchronous satellite 'Early Bird' appeared to be correlated with the growth of $E_{s}$ layer critical frequency, $f_{o} E_{s}$. Aarons and Whitney (1968) showed that the mid-day summer scintillation has a high probability of occurrence when $f_{o} E_{s}>5 \mathrm{MHz}$. Whereas, Singleton and Lynch (1962) examined the correlation between the mean scintillation index for each pass and the critical frequency of $E_{s}$ as recorded at Brisbane and suggested that scintillation does not appear to be associated with $E_{s}$. Although a high value of $f_{o} E_{s}$ may sometimes be associated with scintillation, the precise characteristics of $E_{s}$ layer which causes scintillation are yet to be identified. Recently, Patel et al (2007) presented the preliminary results of the analysis of VHF scintillations recorded during the daytime period from 1991 to 1999 at low latitude station Varanasi to study the behaviour of $E_{s}$ irregularities. After the analysis of few samples of daytime scintillation data they reported spectral index of overhead $E_{s}$ irregularities between -2 and -9 with intermediate scale sizes. These results are very interesting and useful for the low latitudes ionospheric E-region irregularities linked with daytime scintillation. The effect of magnetic activity and solar activity on the occurrence of daytime scintillation was not attempted previously. To complete this preliminary analysis we have analyzed more daytime scintillation datasets recorded at low latitude station Varanasi during the period 1991 to 1999 . We have also included recent daytime scintillation dataset of 2008 , which is a minimum sunspot year.

In this paper, daytime VHF amplitude scintillations recorded during the last decade of twentieth century as well as recent year of 2008 at the low latitude station Varanasi is analyzed to study the complete characteristics of daytime scintillations producing E-region irregularities during the active solar and magnetic periods. The experimental setup of scintillation recording and method of data analysis is described in section 2. The diurnal and seasonal variation of these daytime scintillation associated E-region irregularities has been studied in section 3 . We have tried to examine the association of daytime scintillation with $E_{s}$ irregularities in section 4 . The complete spectral analysis and auto-correlation analysis of daytime scintillations is described in section 5. Finally, section 6 summarizes the results of the present study. 


\section{Experimental observations and data analysis}

The amplitude scintillations of $250 \mathrm{MHz}$ signal transmitted from geostationary satellite FLEETSAT situated at $73^{\circ} \mathrm{E}$ longitudes were monitored continuously at Varanasi using a fixed frequency VHF receiver and strip chart recorder (Singh 1993). The receiver was calibrated at the interval of three months using the method described by Basu and Basu (1989) by disconnecting antenna from the receiver and connecting with a calibrating signal source using RF signal generator at $250 \mathrm{MHz}$. The dynamic range of the receiver was about $20 \mathrm{~dB}$ and most of our scintillation data were recorded on strip chart, which is calibrated as $1 \mathrm{~cm}=2.54 \mathrm{~dB}$. In addition to the normal chart recorder, data were also recorded digitally, at the sampling rate of $1 \mathrm{~Hz}$ on a few nights. The scintillation at Varanasi predominantly is observed in the pre-midnight periods in small patches with duration $<30$ minutes (Singh and Singh 1997; Singh et al 2004). VHF scintillation data recorded during daytime for the period January 1991 to December 1993 in the declining phase of solar cycle and April 1998 to December 1999 in the ascending phase of the next solar cycle as well as recent year of January 2008 to December 2008 have been analyzed in this study. The amplitude scintillation having peak-to-peak variation greater than $3 \mathrm{~dB}$ was included in the analysis. The scintillation index in $\mathrm{dB}$ has been scaled manually every 15 minutes by measuring peak-to-peak $P_{\max }$ - $P_{\text {min }}$ excursion in $\mathrm{dB}$ and using a calibration chart and conversion chart (Whitney et al 1969), where $1 \mathrm{~dB}=12 \%$ scintillation index, $P_{\max }$ is the power amplitude of the third peak-to-peak down from the maximum excursion and $P_{\min }$ is the power amplitude of the third level up from the minimum excursion. The similar method of analysis was adopted by All India Coordinated Program of Ionospheric and Thermospheric Studies (AICPITS) of Department of Science, Government of India (Chandra et al 1993; Kumar et al 2000; Singh et al 2004, 2006; Vijayakumar et al 2007). Typical examples of daytime scintillations recorded at low latitude station Varanasi are shown in figure 1. In general, the observed daytime scintillations at Varanasi are weak and of slow fading rate. The strong and fast fading rate daytime scintillations are rarely observed at our low latitude station Varanasi. We have also observed quasi-periodic scintillations with ringing pattern in plenty of numbers during daytime. We have observed four types of daytime scintillations recorded at Varanasi which is shown in figure 1 as; type A: weak scintillation with slow fading rate (figure 1a), type B: weak scintillation with fast fading rate, type C: quasiperiodic scintillation with short ringing pattern

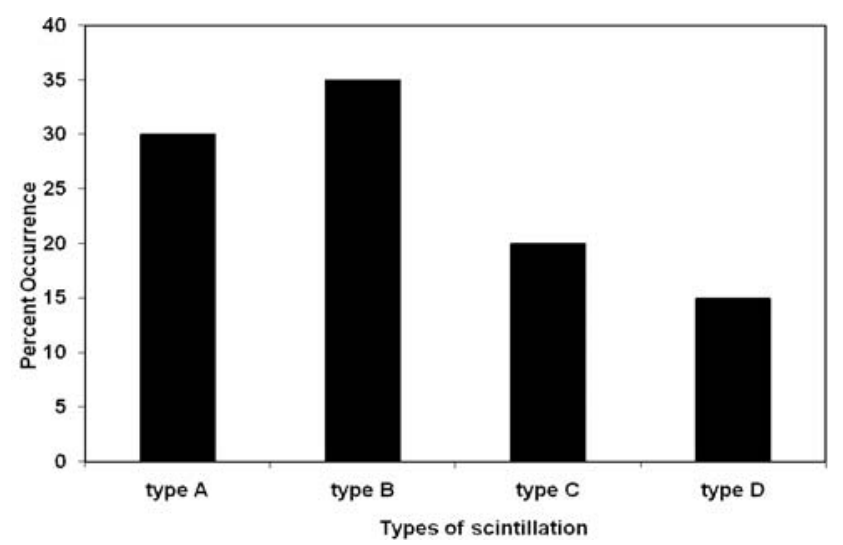

Figure 2. The percentage occurrence of different types of daytime scintillations observed at Varanasi.

(figure 1c) and type D: long duration quasi-periodic scintillation with ringing pattern (figure 1d). The percentage occurrence of these four types of daytime scintillations is presented in figure 2 which shows that percentage occurrence of type B scintillation is maximum around $35 \%$ whereas type D of long duration quasi-periodic scintillation have minimum occurrence of $15 \%$ with $30 \%$ occurrence of type $\mathrm{A}$ and $20 \%$ of that of type C. The detailed analysis of quasi-periodic scintillations, their theoretical modeling and simulation of different types of quasi patches are studied by Patel et al (2009). From figures 1 and 2 we observe that the total percentage occurrence of periodic scintillation with ringing patterns of type C (20\%) and type D (15\%) becomes about $35 \%$. This periodic occurrence of daytime scintillations may be due to the periodic variations of the gravity waves, which is assumed to be the governing process to generate the ionospheric irregularities in daytime (Woodman et al 1991; Tsunda et al 1994; Bourdillon et al 1997). The percentage occurrence of scintillation, scintillation index $\left(S_{4}\right)$, autocorrelation function and power spectra have been computed. To compute auto-correlation function and scintillation index $S_{4}$, total 100 samples of digital data each of 60 seconds have been analyzed and half de-correlation time, $\tau$ has been computed for individual sample. Power spectra have been computed for 50 samples, each digital sample of six minute duration and spectral index has been determined. These parameters yield information about temporal features of ionospheric E-region irregularities.

Since there is no nearby available station for ionogram data during our analysis period of 1991 to 1999 , we have used the ionogram data recorded at the nearest available station Ahmedabad (geographic lat. $=23^{\circ} \mathrm{N} ; \quad$ long. $=72.4^{\circ} \mathrm{E}, \quad$ dip angle $=33.8^{\circ}$, sub-ionospheric $\operatorname{dip}=30.7^{\circ}$ ) to examine the association of daytime scintillation 


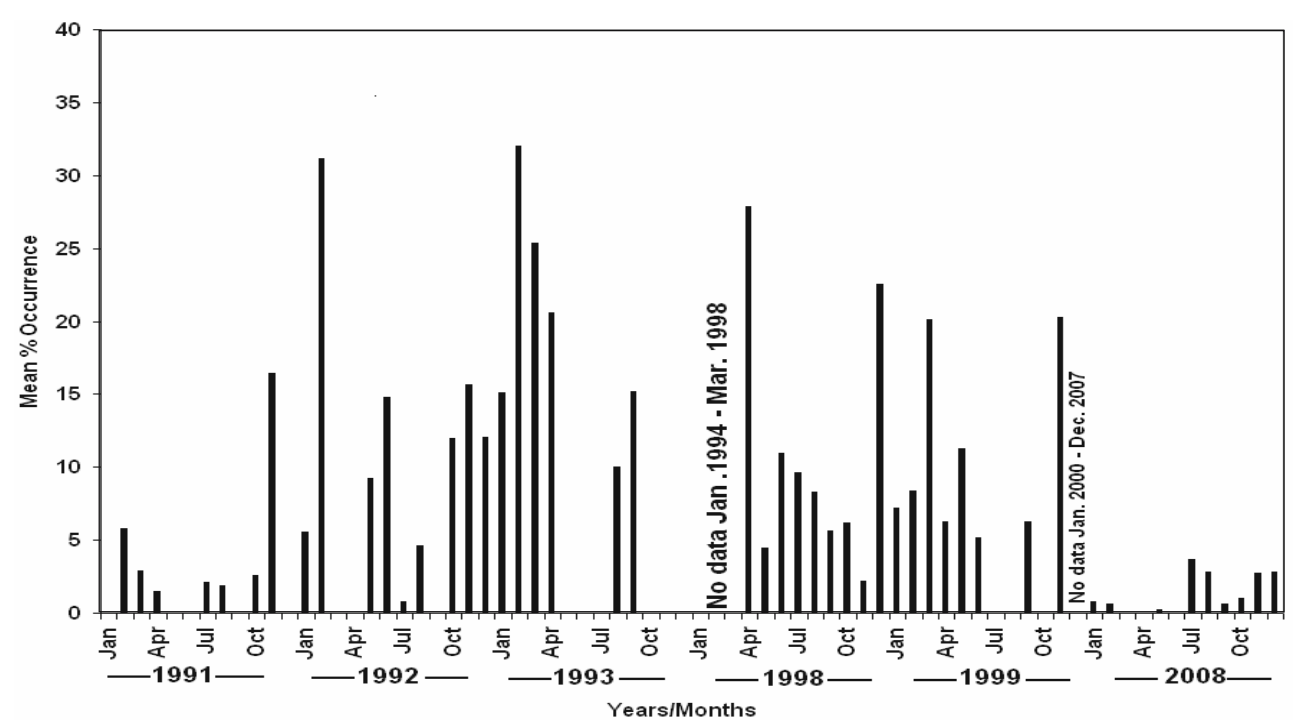

Figure 3. Month-to-month variation of the mean percentage occurrence of daytime scintillations for the years January 1991-December 1993, April 1998-December 1999 and year 2008.

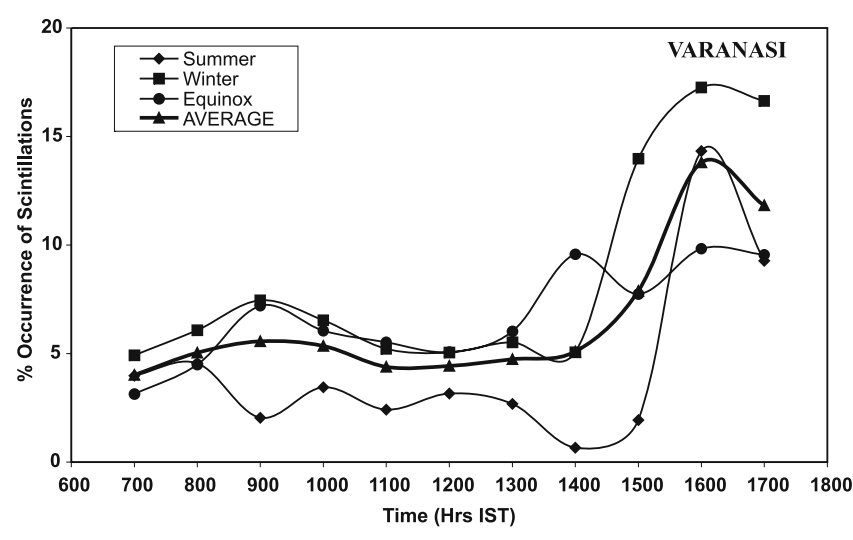

Figure 4. The diurnal variation of percentage occurrence of daytime scintillation for different seasons.

with $E_{s}$ irregularities. To study the effect of magnetic activity on the occurrence of daytime scintillation, we have chosen five most quiet days and five most disturbed days for each month from the data supplied by World Data Center, Japan website (http://swdcwww.kugi.kyotou.ac.jp/qdays/index.html). To study the effect of solar activity, the solar flux $(10.7 \mathrm{~cm})$ data was taken from the NOAA website (http://www.ngdc. noaa.gov/stp/SOLAR/ftpsolarradio.html).

\section{Results and discussions}

\subsection{General features}

Month-to-month variation of the mean percentage occurrence of daytime scintillations (06:0018:00 IST) for the years 1991-1993, 1998-1999 and 2008 observed at Varanasi is shown in figure 3.
The activity is maximum in winter months, moderate in equinox and minimum in summer months. The diurnal variation of occurrence of daytime scintillation for different seasons is shown in figure 4, which shows the maximum occurrence around 15:45 h IST (Indian Standard Time) during all seasons. The maximum occurrence of daytime scintillation in the late afternoon shows that they may be associated with the occurrence of blanketing type of the $E_{s}$ layer at low latitude/magnetic equator (Chandra and Rastogi 1975). The fade rate is generally observed slow for the daytime scintillations. At Varanasi daytime scintillations occur in small patches and average patch duration is usually $<20$ minutes. DasGupta and Kersley (1976) have also shown that in $45 \%$ of the cases the daytime scintillation lasted for $15 \mathrm{~min}$ or less. Assuming that the irregularities causing the daytime scintillation are drifting across the line of propagation of the signal, the above results indicate the patchy nature with small horizontal scale of the irregularity clouds. At mid-latitudes, daytime scintillation occurrence maximizes during summer months (Aarons et al 1963). Hajkowicz and Dearden (1988) have studied the characteristics of radio waves scintillations over a solar cycle (1973-1985) using the $150 \mathrm{MHz}$ transmission from polar orbiting satellite at Brisbane and found a pronounced increase in daytime scintillations in southern winter throughout the solar cycle. The lifetime of $E_{s}$ clouds during sunspot minima is considerably larger than during sunspot maxima (Chavdarov et al 1966). It is true that at low latitude $E_{s}$ activity is pronounced in summer as discussed in previous results at low latitude but our daytime scintillation occurrence statistics peaks in winter 


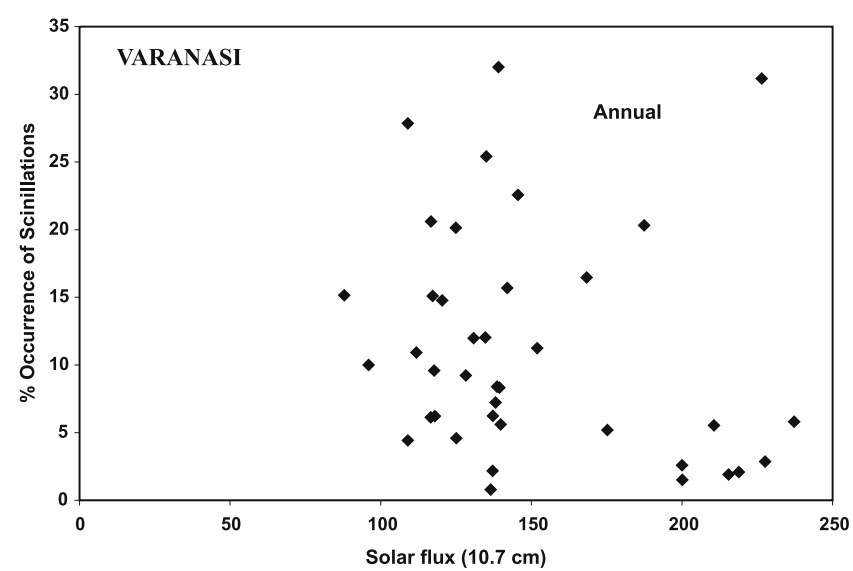

Figure 5. The variation of daytime scintillation occurrence rate with solar flux $(10.7 \mathrm{~cm})$.

as compared to summer as shown in figure 4. This new and appropriate result from the other previous results may be the subject of further study using simultaneous observations of daytime scintillation and $E_{s}$ irregularity shown by ionogram or radar to investigate this discrepancy. At Varanasi plenty of observed daytime scintillations are of quasiperiodic or periodic. This periodic occurrence of daytime scintillations may be due to the periodic variations of the gravity waves, which is assumed to be the governing process to generate the ionospheric irregularities in daytime (Woodman et al 1991; Tsunda et al 1994). Periodic plumes of rapidly rising equatorial irregularities detected by radars suggest that gravity waves propagating in the neutral atmosphere act as seeds for the ionospheric irregularities (Tsunda et al 1994).

\subsection{Effect of solar activity}

To study the effect of solar activity, the variation of daytime scintillation occurrence rate with solar flux $(10.7 \mathrm{~cm})$ is shown in figure 5 , which shows scattered points to lead to any observable conclusion. Hajkowicz and Dearden (1988) showed an increase in the daytime scintillations at Brisbane during a period of sunspot minimum (1973-1985). They also found an increase in quasi-periodic scintillations with a decrease in the sunspot number. The scattered plot of solar flux with scintillation occurrence
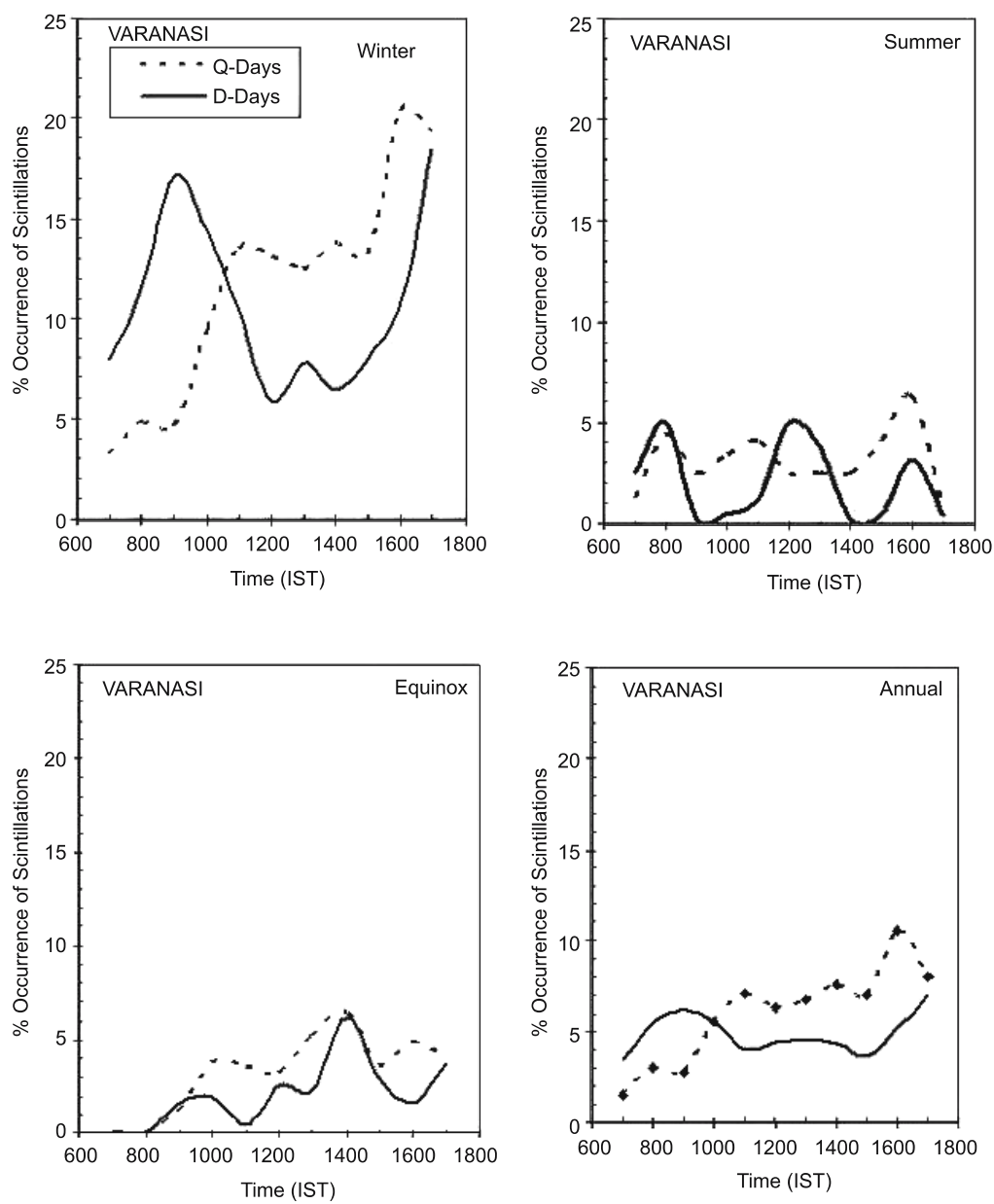

Figure 6. The seasonal and annual variations of percentage occurrence rate of the daytime scintillations on quiet days (Q) and disturbed days (D). 

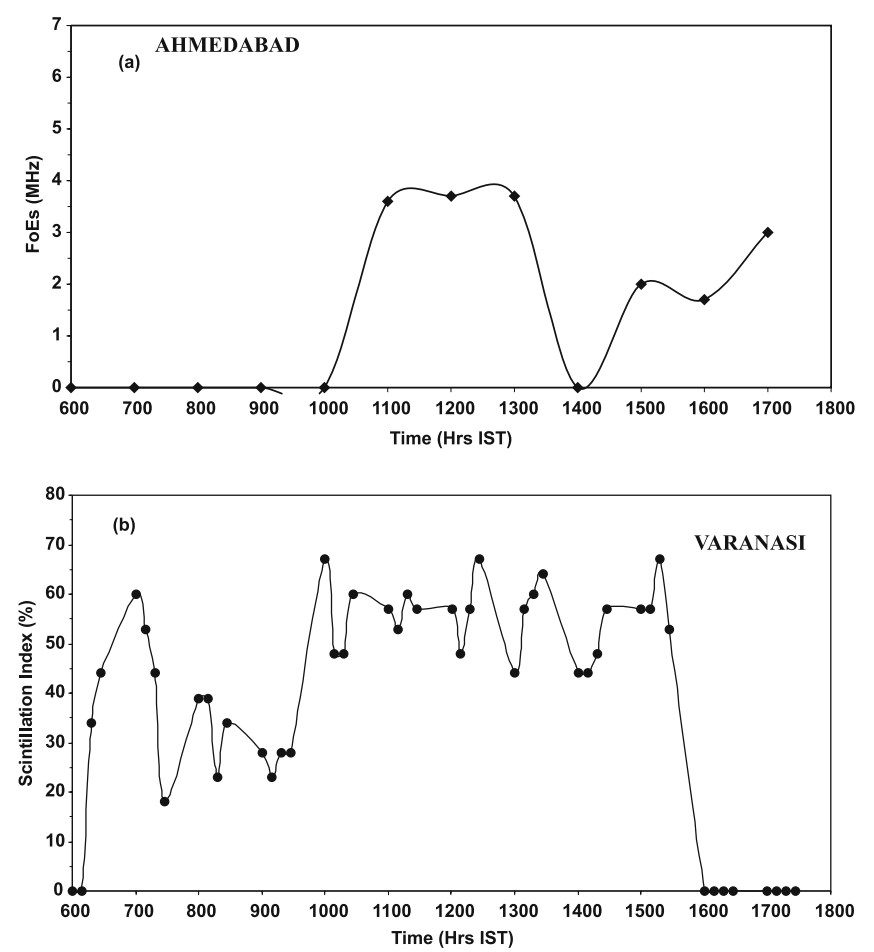

Figure 7. A typical example of simultaneous occurrence of daytime scintillation and corresponding associated $E_{s}$ irregularities on 19 December 1998. (a) The variation of critical frequency of the $E_{s}$ layer $\left(f_{o} E_{s}\right)$ with time. (b) The variation of scintillation index with time.

at our station may be apparently because of limited occurrence of scintillations during daytime.

\subsection{Effect of magnetic activity}

The effect of magnetic activity was examined by comparing scintillation occurrence rates of five international quiet days (Q) and five international disturbed days (D) in each month. Percentage occurrence rates of the scintillations on $\mathrm{Q}$ - and D-days derived from daytime scintillation data for winter, summer, equinox and annual variations are shown in figure 6 . On disturbed days in winter and equinox, daytime scintillations are seen to be inhibited during the whole day except in early morning hours before 10:00 IST. In summer season, daytime scintillations on disturbed days are more pronounced around mid-day but suppressed in the early morning hours and evening hours. On an annual basis a clear suppression of daytime scintillation on the D-days is seen after 10:00 IST.

\section{Association of daytime scintillation with sporadic-E irregularities}

Since there is no nearby available station for ionogram data during our analysis period of 1991 to 1999 , we have used ionograms of $E_{s}$ recorded
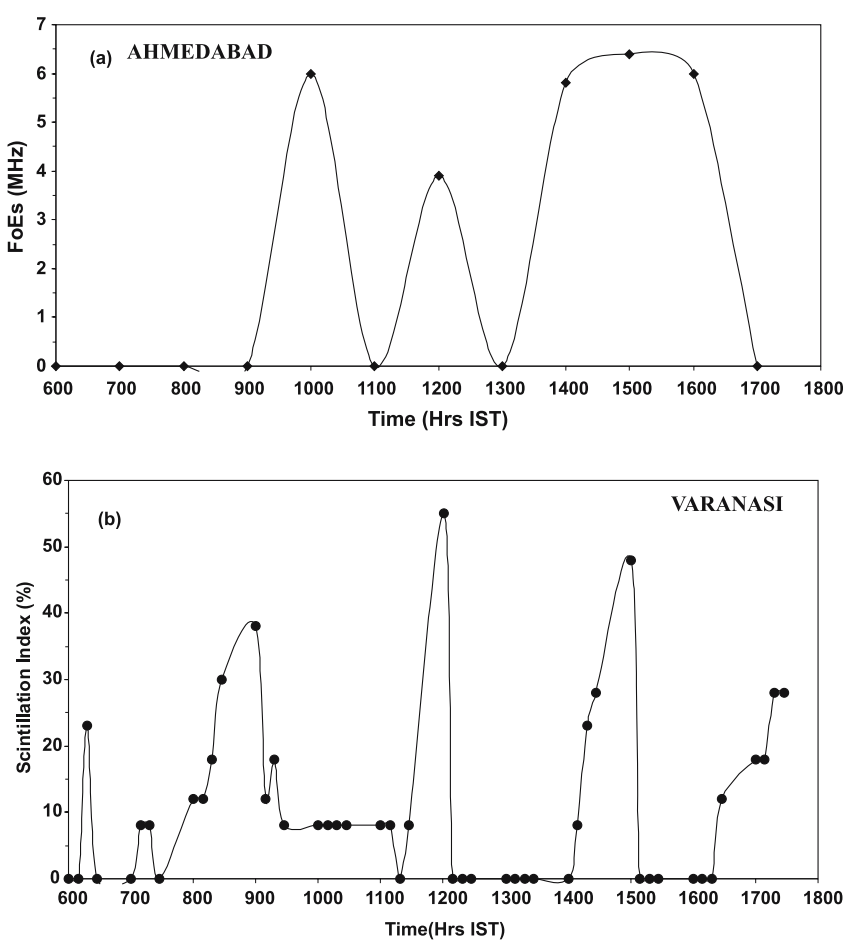

Figure 8. A typical example of simultaneous occurrence of daytime scintillation and corresponding associated $E_{s}$ irregularities on 21 April 1998. (a) The variation of critical frequency of the $E_{s}$ layer $\left(f_{o} E_{s}\right)$ with time. (b) The variation of scintillation index with time.

at the nearest available station Ahmedabad (geographic lat. $=23^{\circ} \mathrm{N}$; long. $=72.4^{\circ} \mathrm{E}, \quad$ dip angle $=33.8^{\circ}$, sub-ionospheric $\operatorname{dip}=30.7^{\circ}$ ) to examine its association with daytime scintillations observed at Varanasi (geographic lat. $=25^{\circ} 15^{\prime} \mathrm{N}$; long. $\left.=82^{\circ} 59^{\prime} \mathrm{E}\right) . E_{s}$ is characterized by variations of the $f_{o} E_{s}$ values. In general, occurrence of daytime scintillation at Varanasi is associated with $E_{s}$ of high $f_{o} E_{s}$ values. It was found that more than $60 \%$ of the daytime scintillation occurrences with duration of more than 15 minutes were associated with $f_{o} E_{s} \geq 5 \mathrm{MHz}$ while the association with $f_{o} E_{s} \geq 4 \mathrm{MHz}$ was $75 \%$. To examine more close association we have tried to study an individual point-to-point correspondence between $E_{s}$ data and daytime scintillation. Two typical examples of simultaneous occurrence of daytime scintillation and corresponding associated $E_{s}$ irregularities are shown in figure $7(\mathrm{a}, \mathrm{b})$ on 19 December 1998 and figure 8(a, b) on 21 April 1998 respectively.

These two events clearly show some correlation between $E_{s}$ and daytime scintillation on diurnal basis but the perfect correlation may not be surmised as the two stations are outlying each other. The work of DasGupta and Kersley (1976), Rastogi et al (1977), and Rastogi (1980) showed a positive relationship between the $E_{s}$ and daytime scintillations. DasGupta and Kersley (1976) have shown that $55 \%$ of the scintillation occurrences with 
VARANASI
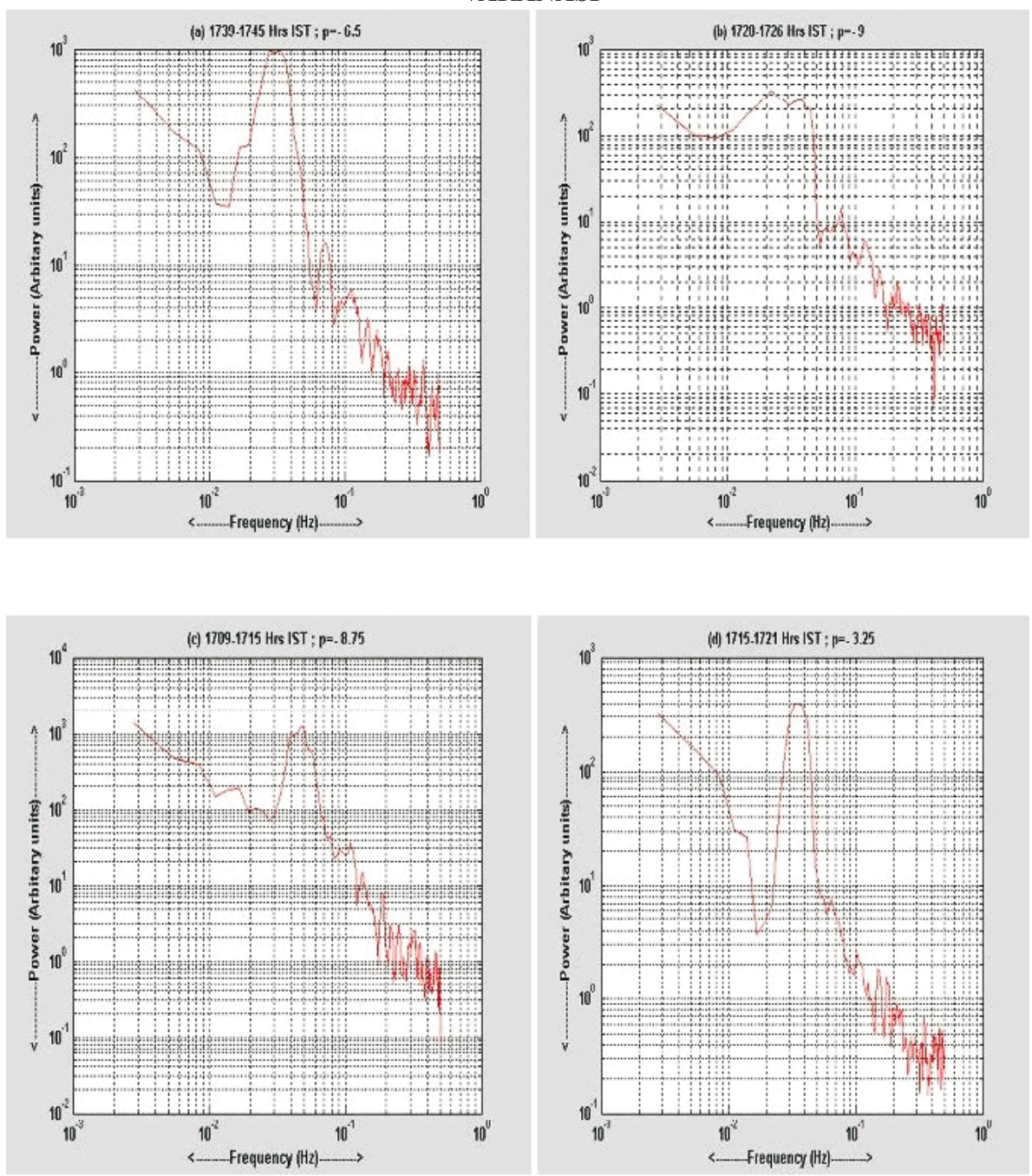

Figure 9. Four typical examples of power spectra computed from daytime scintillation data on (a) 5 December 1992 at 17:39-17:45 h IST, (b) 21 January 1993 at 17:20-17:26 h IST, (c) 21 December 1992 at 17:09-17:15 h IST and (d) 9 February 1993 at $17: 15-17: 21 \mathrm{~h}$ IST.

duration of more than 15 minutes were associated with $f_{o} E_{s} \geq 5 \mathrm{MHz}$ at slough, while the association with $f_{o} E_{s} \geq 4 \mathrm{MHz}$ was $90 \%$. The present data along with earlier results show that a high $E_{s}$ critical frequency, probably $f_{o} E_{s} \geq 4 \mathrm{MHz}$ is a necessary condition for scintillation. Ogawa et al (1989) analyzed mid-latitude data recorded at Kokubunji, Japan and showed that diurnal variation of the scintillation occurrence rate has two maxima consistent with the diurnal variation of the occurrence probability of high $f_{o} E_{s}$ values. After simultaneous observations of vertical soundings and the Faraday fading of the beacons from BE-C satellite recorded at Ahmedabad, Rastogi and Iyer (1976) showed a distinct correlation of strong blanketing $E_{s}$ and the scintillations produced in the radio waves traversing through it even during the daytime at low latitudes. Chandra and Rastogi (1975) have shown that the most probable times for the occurrence of blanketing type of $E_{s}$ layers near magnetic equator/low latitude is late afternoon hours which may be the cause of daytime scintillation peak occurrence around 15:45 h IST at Varanasi.

\section{Spectral analysis of ionospheric E-region irregularities linked with daytime scintillations}

Digital scintillation data is used to compute scintillation index $S_{4}$, auto-correlation function and power spectra, which contain information about relative power of irregularities in different temporal scales. Four typical examples of the power spectra out of thirty samples computed from the daytime scintillation data recorded on (a) 5 December 1992 at 17:39-17:45 h IST, (b) 21 January 1993 at 17:2017:26 h IST, (c) 21 December 1992 at 17:09-17:15 h IST and (d) 9 February 1993 at 17:15-17:21 h IST are shown in figure $9(\mathrm{a}-\mathrm{d})$ respectively. 

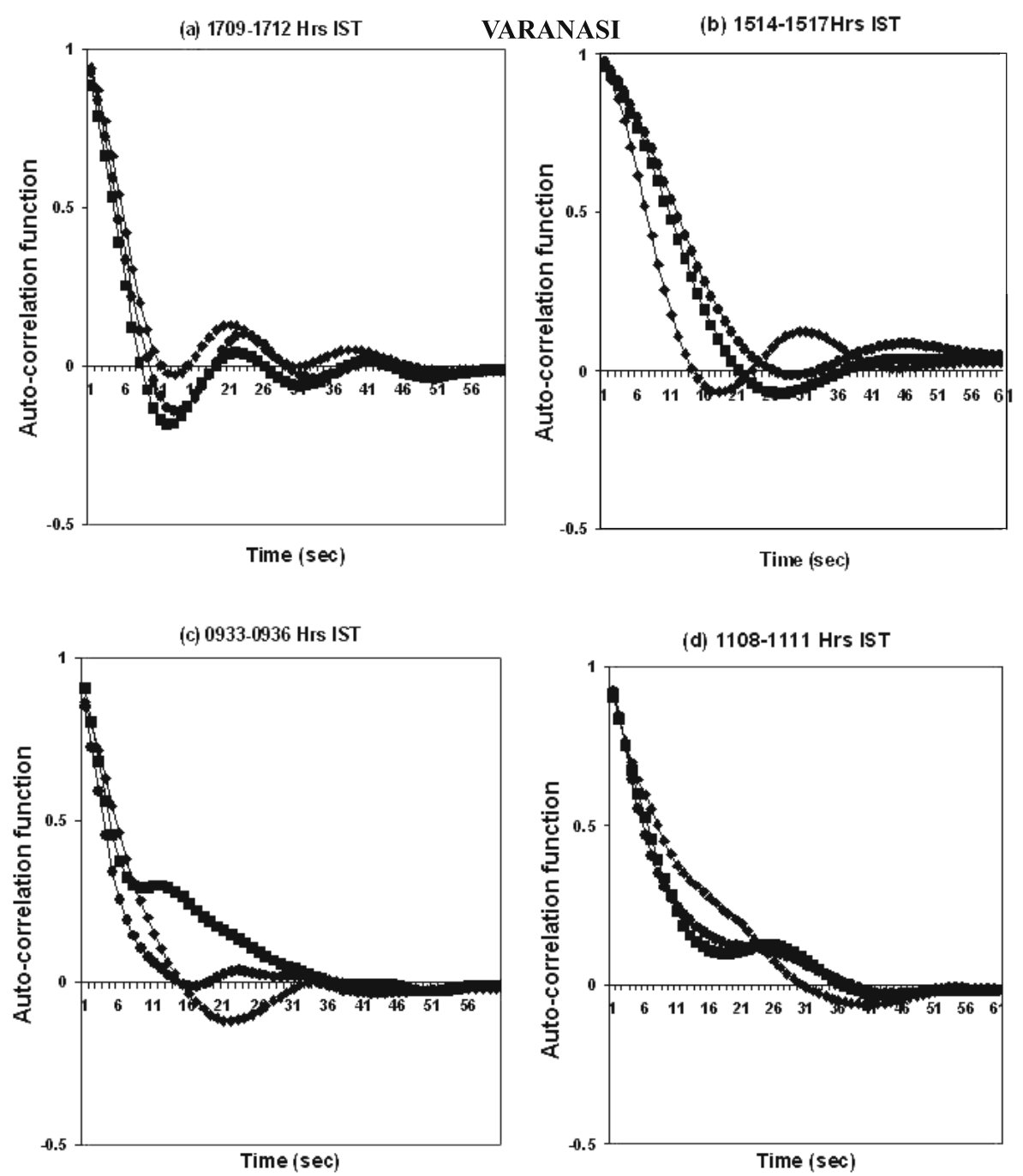

Figure 10. Four typical examples of auto-correlation functions derived from daytime scintillation data on (a) 21 December 1992 at 17:09-17:12 h IST, (b) 2 March 1993 at 15:14-15:17 h IST, (c) 17 April 1998 at 09:33-09:36 h IST and (d) 2 January 1999 at 11:08-11:11 h IST.

These examples show clearly the flat portion towards the lower frequency side, which is due to Fresnel filtering effect. These spectra show maxima around $0.02 \mathrm{~Hz}$. The possible cause of the spectral increase is by additional irregularities with an outer scale size smaller than the size of the first Fresnel zone (Crane 1977). The important features of interest are the slope of the high frequency portion of the scintillation spectra under consideration of weak scatter. The spectra from roll-off portion and onward can be approximated by a straight line. The slopes of the corresponding spectra in the frequency range $0.1 \mathrm{~Hz} \leq f \leq 0.5 \mathrm{~Hz}$ are $-6.5,-9.0,-8.75$ and -3.25 respectively. We have computed spectral slopes of all the 50 samples and found that the spectral index ranges between -2 and -9 with a mean value of -4 . Spectral indices of irregularities derived from in-situ rocket measurements of electron density and electric field is reported to be -1.7 and -5 at frequencies less than $60 \mathrm{~Hz}$ and greater than $60 \mathrm{~Hz}$ (Jahn and Labelle 1998). At Varanasi, we have observed that daytime irregularity spectrum is steeper than the night-time one (Fujita et al 1982; Singh et al 2006).

The size of the irregularities is determined from its definition according to which the size of an irregularity is equal to the distance at which the auto-correlation function falls to 0.5 (Khastgir and Singh 1960). This is possible only when the irregularity patch is moving with constant velocity during the observation period and velocity is known. Few typical examples of auto-correlation functions derived from daytime scintillation data recorded on (a) 21 December 1992 at 17:09-17:12 h IST, (b) 2 March 1993 at 15:14-15:17 h IST, (c) 17 April 1998 at 09:33-09:36 h IST, and (d) 2 January 1999 at 11:08-11:11 h IST are shown in figure 10(a-d) 

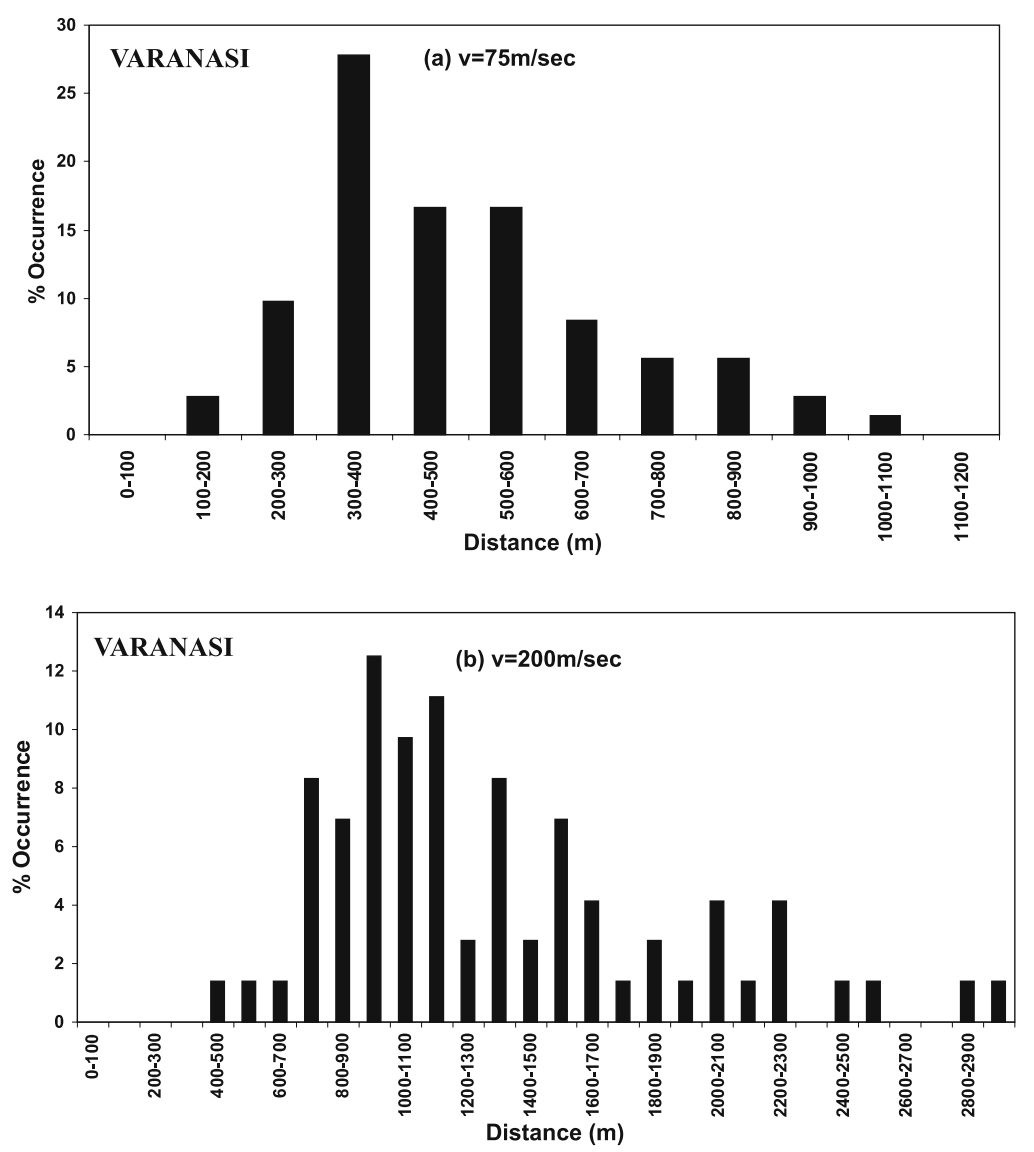

Figure 11. The bar diagrams of percentage occurrence of characteristic length of $E_{s}$ irregularities during the years 1991-1993, 1998-1999 and 2008 (a) for minimum range of characteristic length of $E_{s}$ irregularities taking drift velocity as $75 \mathrm{~m} / \mathrm{s}$ and (b) for maximum range of characteristic length of $E_{s}$ irregularities taking drift velocity as $200 \mathrm{~m} / \mathrm{s}$.

respectively. According to figure 10(a) the half de-correlation time, $\tau$ for three different cases are $\tau_{1}=4.9 \mathrm{~s}, \tau_{2}=3.8 \mathrm{~s}$ and $\tau_{3}=4.2 \mathrm{~s}$. Considering the minimum and the maximum drift velocities of irregularities observed over Varanasi as $75 \mathrm{~m} / \mathrm{s}$ and $200 \mathrm{~m} / \mathrm{s}$ (Singh et al 2006), we have estimated the minimum and the maximum range of characteristic length of the ionospheric E-region irregularities linked with daytime scintillations. We have computed characteristic length of 100 samples and found that it varies between $100 \mathrm{~m}$ and $1100 \mathrm{~m}$ for the minimum drift velocity and for the maximum drift velocity, it varies between $400 \mathrm{~m}$ and $3000 \mathrm{~m}$. Two bar diagrams of percentage occurrence of characteristic length of ionospheric E-region irregularities linked with daytime scintillations over Varanasi during 1991 and 1999 are shown in figure 11(a, b). Figure 11(a) shows the bar diagram of occurrence rate for the minimum range of characteristic length of daytime scintillations producing ionospheric E-region irregularities, which belongs to intermediate scale range with occurrence peak around $300 \mathrm{~m}$; whereas figure 11(b) shows the bar diagram of occurrence rate for the maximum range of characteristic lengths with occurrence peak around $1000 \mathrm{~m}$. Rastogi and Iyer (1976) estimated the width of $E_{s}$ irregularities around $300 \mathrm{~m}$, whereas Somayajulu et al (1977) reported between $800 \mathrm{~m}$ and $924 \mathrm{~m}$. Ogawa et al (1989) reported horizontal scale lengths of the E-region irregularities to range from $20 \mathrm{~m}$ to $600 \mathrm{~m}$. Basu et al (1977) have shown that irregularities for daytime scintillations cover the scale size range at least few meters to $1 \mathrm{~km}$.

The scintillation index $S_{4}$ for daytime scintillation at Varanasi mainly varies between 0.4 and 0.8 , which shows that the daytime scintillations are of moderate type. A typical example of variation of scintillation index, $S_{4}$ on 9 April 1993 is shown in figure 12. The variation of half de-correlation time $(\tau)$ with $S_{4}$ index is shown in figure 13, which shows a scattered plot of $\tau$ with $S_{4}$. From this figure it is clear that the half de-correlation time is almost independent of scintillation index, $S_{4}$. This may be due to the fact that the half de-correlation time is controlled by the Fresnel scale size and not by the perturbation level (Franke and Liu 1983).

In general, it is observed that the characteristics of ionospheric E-region irregularities linked with daytime scintillations determined by us are in 


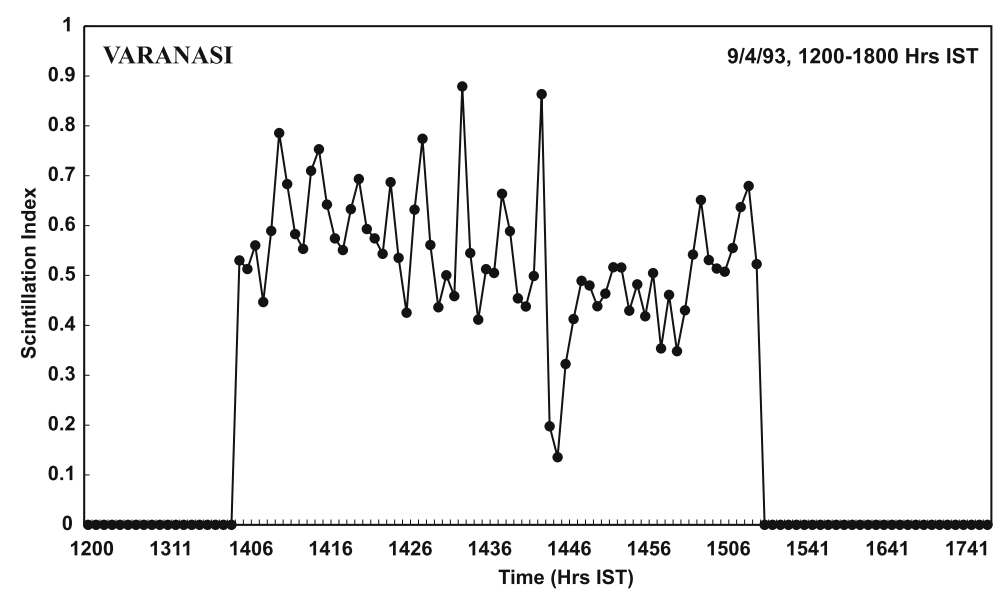

Figure 12. A typical example of variation of scintillation index on 9 April, 1993.

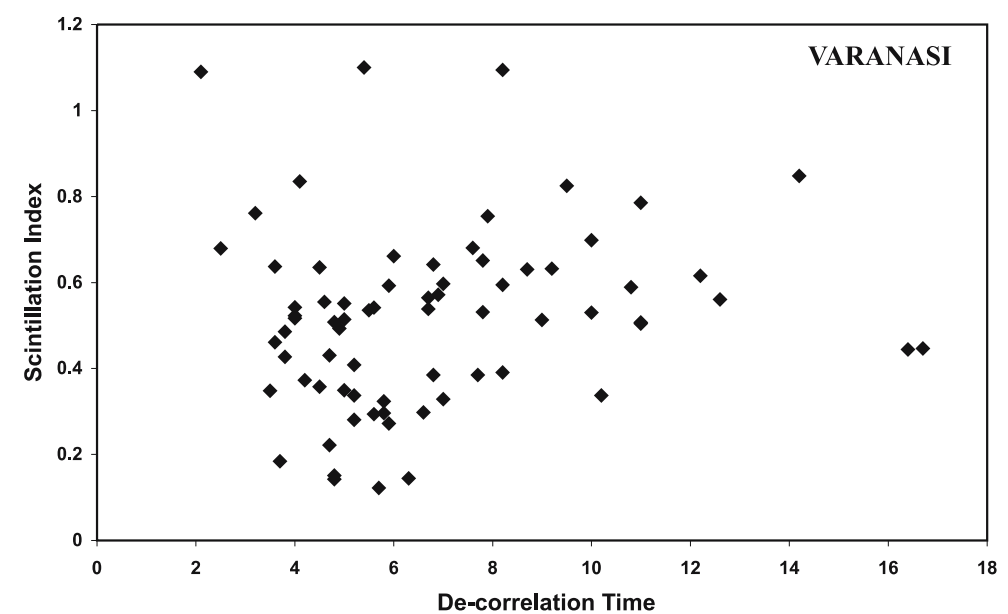

Figure 13. The variation of half de-correlation time $(\tau)$ with scintillation index $\left(S_{4}\right)$.

good agreement with those reported for other low latitude stations.

\section{Summary}

The study revealed that daytime VHF scintillations particularly in the late afternoon hours are due to ionospheric E-region irregularities. It has been found that a high $E_{s}$ critical frequency, probably $f_{o} E_{s} \geq 4 \mathrm{MHz}$, is a necessary condition for daytime scintillation. The occurrence rate of daytime scintillation shows that in general, the associated ionospheric E-region irregularity is maximum during winter months, moderate during equinox months and minimum during summer months. The diurnal variation of occurrence of daytime scintillations at Varanasi shows two peaks at 09:00 h IST and 15:45 $\mathrm{h}$ IST respectively, which are roughly the most probable times for the occurrence of blanketing type of $E_{s}$ layer at low latitudes/magnetic equator (Chandra and Rastogi 1975).
There is no effect of solar activity on the occurrence of daytime scintillations. The enhancement in magnetic activity leads to a suppression of occurrence of daytime scintillation during equinox and winter months, except in early morning hours whereas an enhancement is observed in summer months during mid-day. The auto-correlation and power spectral analysis shows that the spectral index of overhead daytime scintillation producing ionospheric E-region irregularity generally ranges between -2 and -9 , with mean value of -5.5 . Since the estimated characteristic length of these irregularities depends upon the velocity, we obtained a minimum range $(100-1100 \mathrm{~m})$ with occurrence peak around $300 \mathrm{~m}$ and a maximum range (400-3000 m) with occurrence peak around $900 \mathrm{~m}$ for the scale length of irregularities observed over Varanasi. It is clearly seen that the daytime scintillation producing ionospheric E-region irregularity parameters determined by us are in good agreement with those reported for low latitudes. Further, a more detailed study of these events in 
relation to different types of $E_{s}$ is desirable and proposed to be undertaken in future.

\section{Acknowledgements}

This work is partly supported by DST, New Delhi under SERC project and partly by ISRO, Bangalore under CAWSES program. R P Patel thanks DST for the award of FAST TRACK fellowship (SR/FTP/PS-12/2006).

\section{References}

Aarons J, Mullen P and Basu S 1963 Geomagnetic control of satellite scintillations; J. Geophys. Res. 68 33,159.

Aarons J and Whitney H E 1968 Ionospheric scintillation at $136 \mathrm{MHz}$ from a synchronous satellite; Planet. Space Sci. 16 21-28.

Anastassiadis M, Matsoukas D and Moraitis G 1970 40-MHz ionospheric scintillation and the sporadic-E layer; Radio Sci. 5 953-957.

Basu S, Aarons J, Balsley and Ben B 1977 On the nature of electrojet irregularities responsible for the daytime VHF scintillations; J. Geophys. Res. 82 5262-5266.

Basu S and Basu Su 1989 Scintillation technique for probing ionospheric irregularities in World Ionospheric/Thermospheric studies (WITS) Handbook (ed.) Liu C H, SCOSTEP University of Ill., Urbana, 2 128-130.

Bourdillon A, Lefur E, Haldoupis C, Roux Y Le, Menard J and Delloue J 1997 Decameter mid-latitude sporadic-E irregularities in relation with gravity waves; Ann. Geophys. 15 925-934.

Chandra H and Rastogi R G 1975 Blanketing sporadic E layer near the magnetic equator; Geophys. Res. 80 149-153.

Chandra H, Vyas G D, Rao D R K, Pathan B M, Iype A, Ram Sekran B, Tyagi T R, Vijaykumar P N, Singh L, Iyer K N, Pathak K N, Gwal A K, Sushil K, Singh R P, Singh U P, Singh B, Jain V K, Navaneeth G N, Koparkar P V, Rama Rao P V S, Jayachandran P T, Sriram P, Santa Rao N Y S, Das Gupta, A, Basu K and Rastogi R G 1993 Coordinated multi-station VHF scintillation observations in India during March-April 1991; Ind. J. Radio Es Space Phys. 2269.

Chavdarov S S, Chernysheva S P and Shatkhin Kh Z 1966 Stability of reflection from sporadic-E layers and solar activity; Geomagn. Aeron. 6109.

Crane R K 1976 Spectra of ionospheric scintillation; J. Geophys. Res. 81 2041-2050.

Crane R K 1977 Ionospheric scintillation; Proc. IEEE 65 180-199.

DasGupta A and Kersley L 1976 Summer daytime scintillations and sporadic-E; J. Atmos. Terr. Phys. 38 615-618.

Franke S J and Liu C H 1983 Observations and modeling of multi-frequency VHF and GHz scintillations in the equatorial region; J. Geophys. Res. 88 7075-7085.

Fujita M, Sinno K and Ogawa T 1982 Frequency dependence of ionospheric scintillations and its application to spectral estimation of electron density irregularities; J. Atmos. Terr. Phys. 44 13-18.

Goodman J 1967 Some evidence of $E_{s}$-layer effects upon $136 \mathrm{MHz}$ radio waves; J. Atmos. Terr. Phys. 29 607-612.
Hajkowicz L A and Dearden D J 1988 Observations of random and quasi-periodic scintillations at southern midlatitudes over a solar cycle; J. Atmos. Terr. Phys. 50 511-517.

Hajkowicz L A and Minakoshi H 2003 Mid-latitude ionospheric scintillation anomaly in the Far East; Ann. Geophys. 21 577-581.

Jahn J M and LaBelle J 1998 Rocket measurements of highaltitude spread-F irregularities at the magnetic dip equator; J. Geophys. Res. 103(A10) 23,427-23,441.

Khastgir S R and Singh R N 1960 The size of moving irregularities in the F-region and spread angle of the radio waves scattered from them; J. Atmos. Terr. Phys. 18 $123-126$.

Kumar S, Gwal A K, Rama Rao P V S, Jayachandran P T, Prasad S V V D, Singh R P, Singh U P, Dasgupta A, Basu K, Sethuraman R, Pathan B M, Rao D R K, Banola S, Kesava Rao P S, Naidu A, Tyagi T R, Vijaykumar P N, Chandra H, Vyas G D, Singh B, Chauhan P, Iyer K N, Pathak K N, Shalgaonkar C S, Vyas B M and Rastogi R G 2000 Co-ordinated observations of VHF scintillations in India during FebruaryMarch 1993; Ind. J. Radio Space Phys. 2922.

Ogawa T, Suzuki A and Kunitake M 1989 Spatial distribution of mid-latitude sporadic-E scintillations in summer daytime; Radio Sci. 24 527-538.

Patel K, Singh A K, Patel R P and Singh R P 2007 Ionospheric scintillations by sporadic-E irregularities over low latitude; Bull. Astr. Soc. India 35 625-630.

Patel K, Singh A K and Singh R P 2009 Observations and modeling of quasi-periodic scintillations observed at low latitude; J. Phys. C. S. (in press).

Rastogi R G and Iyer K N 1976 Ionospheric scintillations induced by cloud of intense sporadic-E layer; Curr. Sci. $45685-686$.

Rastogi R G, Deshpande M R, Murthy B S and Davies K 1977 Daytime satellite radio scintillations and sporadic-E near the magnetic equator; Geophys. Res. Lett. 4 113.

Rastogi R G 1980 Daytime radio wave scintillations in the equatorial electrojet regions; Ind. J. Radio Space Phys. 9 219.

Singleton D and Lynch G 1962 The scintillation of the radio transmissions from Explorer VII-I; J. Atmos. Terr. Phys. 24 353-360.

Singh A K 1993 Study of VLF whistlers and VHF scintillations, Ph.D. Thesis, Banaras Hindu University, Varanasi.

Singh A K and Singh R P 1997 Observations and modelling of nocturnal ionospheric irregularities in low latitude region; J. Geomag. Geoelectr. 49 1115-1129.

Singh R P, Patel R P and Singh A K 2004 Effect of solar and magnetic activity on VHF scintillations near the equatorial anomaly crest; Ann. Geophys. 22 2849-2860.

Singh A K, Patel R P and Singh R P 2006 Statistical features of overhead ionospheric irregularities and its generation mechanism at low latitude; J. Atmos. Solar Terr. Phys. 68 1116-1124.

Somayajulu Y V, Garg S C and Vijay Kumar P N 1977 Scintillation Studies using ATS-6 Radio Beacons at Delhi; Indian J. Radio Space Phys. 6 250-256.

Tsunda R T, Fukao S and Yamamoto M 1994 On the origin of quasi-periodic radar backscatter from mid-latitude sporadic-E; Radio Sci. 29 349-365.

Vijayakumar $\mathrm{P} N$, Tyagi $\mathrm{T}$ R, Singh L, Chandra H, Vyas G D, Rao D R K, Pathan B M, Iype A, Ramsekaran B, Naidu A, Sadique S M, Iyer K N, Pathak K N, Gwal A K, Kumar S, Singh R P, Singh U P, 
Singh B, Kumar P, Navneeth G N, Koparkar P V S, Ramarao P V S, Jaychandran $\mathrm{P}$ T, Sriram P, Sethuraman R, Dasgupta A, Basu K and Rastogi R G 2007 Some features of plasma bubble induced scintillations during the AICPITS campaigns of 1991; Ind J. Radio Space Phys. 36 91-102.
Whitney H E, Aarons J and Malik C A 1969 Proposed index for measuring ionospheric scintillation; Planet. Space Sci. 17 1069-1073.

Woodman R F, Yamamoto M and Fukao S 1991 Gravity wave modulation of gradient drift instabilities in midlatitude sporadic-E; Geophys. Res. Lett. 18 1197-1200.

MS received 5 June 2009; revised 15 September 2009; accepted 16 September 2009 